\title{
AC 2007-2268: STUDENT CURRICULUM MAPPING: A MORE AUTHENTIC WAY OF EXAMINING AND EVALUATING CURRICULUM
}

\section{Lisa Romkey, University of Toronto}

Lisa Romkey is the Lecturer, Curriculum, Teaching and Learning with the Division of Engineering Science. In this position, Lisa plays a central role in the continuous improvement of the design and delivery of a dynamic and complex curriculum, while facilitating the development and implementation of teaching and learning initiatives and innovations. Lisa is cross-appointed with the Department of Curriculum, Teaching and Learning at OISE/UT (Ontario Institute for Studies in Education at the University of Toronto). Lisa holds a Masters in Curriculum Studies and is currently pursuing a $\mathrm{PhD}$ in higher education at OISE/UT. Research interests include teaching \& learning in higher education, engineering education, first year experience, STSE in higher education and gender issues in science and engineering.

\section{Laura Bradbury, Division of Engineering Science, University of Toronto}

Laura Bradbury is an engineering student at the University of Toronto. She is currently completing her undergraduate degree in Engineering Science, which is a very comprehensive and well respected program. She will be focusing her studies in the field of aerospace engineering and, in particular, flight dynamics and aircraft design. She has held an internship position as a Curriculum Evaluation and Development Associate with the division of Engineering Science. Her research interests include engineering education and engineering design theory. 
Student Curriculum Mapping: A More Authentic Way of Examining and Evaluating Curriculum? 


\section{Student Curriculum Mapping: A More Authentic Way of Examining and Evaluating Curriculum?}

Curriculum mapping is a practice used in schools to encourage teacher collaboration on curriculum organization, integration and assessment. Rather than what is provided on a syllabus constructed before the beginning of classes, the curriculum map provides a description of what is going on in real-time. Curriculum mapping demonstrates both the content and sequence of the curriculum, as well as the goals, objectives or requirements that the curriculum is meeting. It is often used to benchmark against curriculum standards or program objectives, and is helpful in identifying gaps, overlaps, repetitiveness and general need for improvement in a set of curricula.

This paper discusses the outcomes of a project in which two engineering students created curriculum maps of their entire first-year learning experience, as well as two students currently mapping their second year experience. Typically, curriculum mapping would be completed by course instructors, however through student participation in the process, it was estimated that a more relevant view of what is actually learned by the student would be produced. Through reflections from the student, instructors and program administration responsible for curriculum organization and delivery, this paper demonstrates the benefits and challenges of student-led curriculum mapping and how results can be used to improve the overall student learning experience in an engineering program. The benefits specific to an interdisciplinary curriculum, in which courses are developed and delivered by individuals from various departments, are also addressed. 
Introduction

Curriculum mapping is a relatively new technique used to organize and communicate curriculum. The technique is most often used within K-12 schools and boards, but has also been used in colleges and universities that tend to suffer from instructor and course isolation; in other words, faculty who do not have a clear understanding of what is addressed in the courses of their colleagues. This paper describes the initial stages of a large-scale, long-term curriculum mapping project in an undergraduate engineering program at the University of Toronto. While traditionally, the practice is conducted by the instructors who teach the course, or those responsible for curriculum development, this project takes on a new twist in that students, who have experienced the curriculum as the learner, conducted the mapping. Curriculum mapping is said to provide an accurate view of what is actually delivered, and through engaging students in the process, there is an opportunity to determine what is actually learned, from the students' perspective. Through this paper, we look at purpose and practice of curriculum mapping, the process we have taken on, the perceived benefits to students, faculty and administration and the unique benefits achieved through engaging students in this process.

\section{Curriculum Mapping: Purpose and Practice}

Curriculum mapping was developed in response to a lack of communication and readily available information about the curriculum in a given educational setting. It is designed to provide the "whole picture" of the taught curriculum, including relationships between components that may not otherwise be linked, such as undergraduate courses taught in different departments. Curriculum mapping provides a broad picture of the "real" curriculum - what is actually being delivered to the students, as opposed to the "fictional" curriculum, or what is being declared or intended (Harden, 2001) ${ }^{5}$. The curriculum map is usually a diagram that shows the relationships between curriculum elements, or a table/matrix that displays the different elements of the curriculum and the inter-relationship between these elements (Wigal, 2005) ${ }^{10}$. A curriculum map representing an undergraduate program, in its complete form, would include information on each and every learning experience at a very detailed level, across semesters and years. Curriculum mapping demonstrates the content and sequence of the curriculum, and the goals, objectives or requirements that the curriculum is meeting. Curriculum mapping also looks at the time allocated to particular tasks, and how this has an effect on student achievement in particular domains (Clough, James and Witcher, 1996) ${ }^{2}$.

Curriculum mapping is a practice often used in the K-12 education system, where schools and school boards attempt to organize and communicate curriculum in new ways. Curriculum mapping allows a school district to ensure that national and local benchmarks are being met (Declark, 2002) ${ }^{3}$, and ensure all students are receiving the appropriate learning experience, regardless of teacher or school. It also encourages teachers, across grades or disciplines to better coordinate and integrate their curriculum. The practice is also relatively common in medical education, and is evident throughout other undergraduate, graduate and professional programs. Little has been published about curriculum mapping efforts in engineering programs, despite the potential unique benefits to engineering, given factors such as its complexity, the importance of application of theory and the accreditation process. 
The content within curriculum maps vary, but typically include the following broad categories:

- Learning objectives or statements of knowledge/skills/attitudes

- Instructional activities or learning experiences

- Assessment

More specifically, curriculum maps may include:

- Course content

- Essential questions

- Educational strategies

- Information about the educational environment

- Individual learning styles and student information

- Staff and faculty

- Resources

- Scheduling and other administrative information

Curriculum mapping can assist staff, students, instructors and administrators in providing key elements of the curriculum and the relationships between them in a very transparent, straightforward manner (Harden, 2001) $)^{5}$. It also enables a deeper understanding of what is being taught across the board. Through a review of the "whole picture" of the curriculum, one can identify gaps that occur between courses, semesters and years, as well as redundancies that faculty may be unaware of - for example, concepts that are taught repeatedly without the knowledge of its other occurrences in the curriculum. Curriculum mapping can identify misalignments in the curriculum; for example, identifying issues and streamlining the delivery of mathematics and its application in science and engineering sciences. There are often instances where the sequencing of particular learning opportunities needs to be altered to better suit students' learning progression, and these instances can be identified through the thoroughness of the mapping process. Curriculum mapping demonstrates to instructors how their teaching fits into the overall curriculum picture, and how their subject is addressed in other areas of the curriculum

Curriculum mapping can be used to ensure that educational standards, and program or institution-wide objectives are being met to the appropriate magnitude. Where the development of particular skills is important, curriculum maps can be used to identify where and how these skills are being developed, and where improvement is necessary. Curriculum maps can provide an understanding of how we meet both institutional and program goals, and can consider cocurricular as well as curricular activities (Maki, 2004) ${ }^{7}$. Where appropriate (such as across similar courses taught by different instructors), maps can be used to ensure consistency across courses. Curriculum mapping can also help planners ensure that the transition between semesters and years of a program is smooth.

One of the most important benefits of curriculum mapping is determining whether objectives, material delivered and assessment align. An examination of this can help determine the curriculum's clarity and the appropriateness and fairness of assessment. Through examining the length of time actually spent on each particular topic, we can achieve a fair evaluation of the students' perception of what's important in the course, and if time on task does not match 
emphasis on assessment, we can ask ourselves which component of the curriculum needs to be adjusted.

Curriculum mapping can be an integral starting point for curriculum integration, which is essentially the restructuring of learning activities to help students build connections between topics. Transferring knowledge from one context and applying it to another can be a challenging task, and with students learning about a number of different topics in various, independent courses, they must actively extend existing cognitive networks, or construct new networks to hold this new information (Bransford, Brown and Cocking, 1999) ${ }^{1}$. If topics taught in multiple courses are closely related or relevant to each other, students can more easily and effectively retain this information. Essentially, it is difficult to transfer and apply knowledge when information is taught in isolation, or in other words, in individual courses taught by different instructors. As we learn more about how a set of "single-foci" courses has limitations in the promotion of learning and how the proliferation of knowledge requires new methods of management, curriculum integration is becoming more common in university and college programs (McKinney and Yoos, 1998) ${ }^{8}$.

Curriculum mapping has been known to make interesting discoveries about the curriculum of a particular program. For example, in the case of a medical education program (Gjerde, 1981$)^{4}$, it was determined through an ongoing curriculum mapping project that shifts had occurred in course content and test items, and that course objectives were no longer aligned with instruction or assessment. In this same initiative, the project leader also classified learning objectives using Bloom's taxonomy to determine the level of learning objectives - and found that most were in the "knowledge" and "comprehension" domains. Through this process, curriculum planners have evidence to provide suggestions on the implementation of higher-level assessment items.

In the case of an Early Childhood Education Program (Sumsion and Goodfellow, 2004) ${ }^{9}$, an exercise in mapping generic skills (such as literacy, information technology and problem solving) across various curriculum units was conducted. Educators from across the program used particular indicators to give the level reached for each skill in their course: "Assumed" (it's assumed that students already have the skill), "Encouraged", "Modelled", "Explicitly Taught", "Required" and "Evaluated". The project team came across challenges with the interpretation of definitions of the generic skills, but overall the process was found to assist them in identifying general patterns across the program, and also provided a valuable opportunity for reflection.

A final benefit to the process is that it provides focus to staff, students and instructors on the importance of curriculum, teaching and the holistic view of an educational program. Curriculum mapping can call attention to not only its intended factors, but any positive or negative components of the learning experience, such as issues with workload or interesting practices that should be shared between instructors.

\section{Our Project}

Typically, instructors or curriculum planners would conduct the curriculum mapping for a particular program. As our project includes the creation of curriculum maps by students enrolled 
in the curriculum under review, the students involved in the activity were provided the same training that would typically be provided to instructors in terms of clarifying definitions in the map structure and guidance on how to review course material. Throughout the summer of 2006, two students, who had just completed the first year of the engineering program, completed a set of curriculum maps that represented their entire first year experience. Beginning in the fall of 2006, two second-year students set out to develop curriculum maps, as their courses progressed, representing their second-year experience. The four students in total were selected and hired based on their interest in the project, through an open call to students in the program. All four students were part of the same engineering program. The two "mapped" years represent the first roll-out of a new foundation curriculum for the program, and so the timing was right to experiment with new methods of curriculum evaluation.

First, students were introduced to the template, which has been adapted from Jacob's model $(2004)^{6}$ for curriculum mapping. Prior to the review of their course material, the students developed an understanding of the seven curriculum map components, which are as follows:

- Content: What is the big idea, or broad topic covered within the course? What are the major subcategories on which the course spends a great deal of time? What are the major underlying concepts for the big ideas or broad topics?

- Essential Questions: What are the overarching questions that serve to guide instruction and learning? What are the questions that help students link content to the course's "big idea"? What are the questions that will guide teaching and engage students in uncovering the "heart" of the big idea?

- Skills: What are the skills or processes that ensure successful mastery of the course material? What are the skills that students need to be successful at demonstrating the "big idea"? What are the skills that are explicitly addressed in the course?

- Activities: What are the practice activities that are conducted by students to understand the course content?

- Assessment: What is the evidence that demonstrates that students understand the big idea, broad topic or concept? What are the products or performances that students produce through the course? What are the assessments that allow students to demonstrate learning or understanding in multiple ways?

- Learning Objectives: What are the statements of specific learning behaviours, skills, attitudes or abilities connected to the learning goals? Bloom's Taxonomy can be used to describe the learning objectives through the following descriptors:

- identify, name, select, classify (knowledge of facts/concepts)

- show, demonstrate, compute (acquisition of procedural skills)

- distinguish, analyze, criticize, synthesize (thinking, understanding, and application of core concepts)

- create, construct, compose (production of an academic product)

- Resources: What are the specific support materials, books, field trips, videos or websites that are used in conjunction with the course and particular lectures?

Once an understanding of these definitions was established, a process and order was developed that made sense to the students and their conception of their course work and learning: 
1) Ensure all course materials - including lecture notes, study notes, assignments, tests, quizzes, projects, textbooks and other handouts, and the final exam - are on hand for reference

2) Go through the lectures/tutorials/laboratories sequentially and identify, in the following order:
i. Topic
ii. Content
iii. Essential questions
iv. Activities
v. Learning objectives

vi. Skills (include only in this step if the course does not depend heavily on lectures and instead, places emphasis on active learning and practice, such as a laboratory or design course)

\section{vii. Resources}

3) (Optional) If the course is lecture-based, identify skills gained throughout the course at the end of the map.

4) Include methods of assessment in the map by relating the topic of the assessment with the lecture of the same or similar topic

Students created maps that demonstrated an in-depth summary of each course, on a lecture-bylecture basis. Figure 1 represents a 1-week portion of a curriculum map for a first year course in linear algebra. Through reading the map from left to right, one can identify and connect objectives with content and assessment.

\begin{tabular}{|c|c|c|c|c|c|c|c|c|}
\hline Week & Lecture & Topic & Content & Essential Questions & Assessment & Learning Objectives & $\begin{array}{l}\text { Activities } \\
\text { (from } \\
\text { Nicholso } \\
\text { n) }\end{array}$ & Resources \\
\hline 1 & 1 & $\begin{array}{l}\text { Vector } \\
\text { spaces }\end{array}$ & $\begin{array}{l}\text { - Brief review of concepts } \\
\text { learned in MAT190 } \\
\text { - Definition of a vector space } \\
\text { - Axioms for vector addition }\end{array}$ & $\begin{array}{l}\text { - What concepts did we learn } \\
\text { about vectors in MAT190? } \\
\text { - What mathematical objects } \\
\text { behave like vectors? } \\
\text { - What is a vector space? }\end{array}$ & & $\begin{array}{l}\text { - Associate other } \\
\text { mathematical objects } \\
\text { (e.g., functions, matrices) } \\
\text { with vectors } \\
\text { - Define a vector space }\end{array}$ & $\begin{array}{l}{[6.1] 1-4,} \\
8,9,13- \\
15,17-18\end{array}$ & $\begin{array}{l}\text { - Section } 6.1 \text { of } \\
\text { Nicholson } \\
\text { - Chapter } 4 \text { of } \\
\text { Lorimer and } \\
\text { D'Eleuterio }\end{array}$ \\
\hline 1 & 2 & $\begin{array}{l}\text { Vector } \\
\text { spaces }\end{array}$ & $\begin{array}{l}\text { - Definition of a vector space } \\
\text { - Axioms for vector addition } \\
\text { - Axioms for scalar } \\
\text { multiplication } \\
\text { - Consequences of the } \\
\text { axioms (i.e., cancellation } \\
\text { theorem, uniqueness of the } \\
\text { zero) }\end{array}$ & $\begin{array}{l}\text { - What are the axioms a set } \\
\text { must satisfy in order to be } \\
\text { classified as a vector space? } \\
\text { - What propositions follow } \\
\text { from the axioms? }\end{array}$ & $\begin{array}{l}\text { - Test question on } \\
\text { distributive } \\
\text { properties of a } \\
\text { vector space } \\
\text { - Test question on } \\
\text { the cancellation } \\
\text { theorem } \\
\text { - T/F test } \\
\text { questions on vector } \\
\text { spaces }\end{array}$ & $\begin{array}{l}\text { - List the axioms of } \\
\text { vector addition and } \\
\text { scalar multiplication } \\
\text { - Extend the axioms to } \\
\text { prove the cancellation } \\
\text { theorem and the } \\
\text { uniqueness of the zero }\end{array}$ & $\begin{array}{l}{[6.1] 1-4,} \\
8,9,13- \\
15,17-18\end{array}$ & $\begin{array}{l}\text { - Section } 6.1 \text { of } \\
\text { Nicholson } \\
\text { - Chapter } 4 \text { of } \\
\text { Lorimer and } \\
\text { D'Eleuterio }\end{array}$ \\
\hline 1 & 3 & $\begin{array}{l}\text { Vector } \\
\text { spaces }\end{array}$ & $\begin{array}{l}\text { - Brief review of propositions } \\
\text { learned in previous lecture } \\
\text { - Commutative property for } \\
\text { vectors } \\
\text { - Examples of vector spaces } \\
\text { (e.g., column and row spaces) } \\
\text { - Space of functions }\end{array}$ & $\begin{array}{l}\text { - How do we prove the } \\
\text { commutative property for } \\
\text { vectors? } \\
\text { - What are some examples of } \\
\text { vector spaces? }\end{array}$ & $\begin{array}{l}\text { - Test question } \\
\text { requiring students } \\
\text { to determine if a } \\
\text { set of vectors is a } \\
\text { vector space }\end{array}$ & $\begin{array}{l}\text { - Classify a set as a vector } \\
\text { space by proving that the } \\
\text { definitions of addition } \\
\text { and multiplication satisfy } \\
\text { the axioms of vector } \\
\text { addition and scalar } \\
\text { multiplication } \\
\text { - Demonstrate that the } \\
\text { space of functions is a } \\
\text { vector space }\end{array}$ & $\begin{array}{l}{[6.1] 1-4,} \\
8,9,13- \\
15,17-18\end{array}$ & $\begin{array}{l}\text { - Section } 6.1 \text { of } \\
\text { Nicholson } \\
\text { - Chapter } 4 \text { of } \\
\text { Lorimer and } \\
\text { D'Eleuterio }\end{array}$ \\
\hline
\end{tabular}

Figure 1: Segment of a curriculum map for a first year linear algebra course 


\section{Student Perspective}

Students expressed various challenges with the curriculum mapping process, some of which provided valuable insights on their conceptions of the course, their understanding of learning objectives and their perceived outcomes from their educational experience. The following are quotes from three of the four students who participated in the project:

"As a student creating a curriculum map, it is difficult to identify learning objectives because a student would not know what goal the professor had in mind for a particular lecture."

"The identification of skills is a significant part of curriculum mapping. However, in lecture settings, students develop few skills. In courses with a large number of lecture hours, the skills gained are often indistinguishable."

"The learning objectives often get revised (when I'm creating a map)...if a test question is not what I thought was the objective, I add it to the original one, because chances are the original "learning objectives" contained the questions done in the examples."

The students also expressed the challenges of creating the curriculum maps, from an organizational point of view:

"Essential questions and learning objectives require more thought: ideally, the lectures are relatively self-contained, but many lectures continue the previous day's, and halfway through, they'll move on to the next, semi-related topic."

"Sometimes, it requires creativity to pick out the topic(s) of the lecture - there's a fine line between putting so much detail into the map that nobody wants to read it, or not putting enough detail in, and professors who want to find out whether a specific theorem or proof was covered can't."

"Resources are best left until last because you can now search the textbook looking for not only class content, but also examples or homework questions very similar to the test questions."

The students involved in the curriculum mapping project were asked to share some of their perspectives on the benefits and possible uses of the curriculum maps, related to their learning experience. As noted by Haden $(2001)^{5}$, curriculum maps can be used not only for curriculum planning and faculty reflection, but also as a learning or self-assessment tool. Maki (2004) ${ }^{7}$ also strongly proposes the use of curriculum maps as "learning maps" for our students, that provide an overview of the journey and an encouragement to take responsibility for learning at the time of enrollment. Students echoed this ideas:

"The map makes for a very useful course outline - best course outline is a detailed one, in my opinion."

"(If) students start a course armed with the curriculum map, they get an extremely detailed outline of each lecture.” 
"The curriculum map can serve as a helpful self-check for students: can they answer the "essential questions" after the lectures? It also serves as an excellent review document for exams."

"Curriculum maps make learning objectives of a course clearer to the students and assist them to identify how different parts of the course relate to different course goals."

The students also determined potential uses for the maps by faculty and curriculum planners:

"if he or she(the instructor) finds that the students entirely missed the theme, or had trouble understanding what was going on in particular lectures, they could use that to improve the course."

"by reviewing the map, you can note that a concept mentioned in the beginning is explained in more detail later in the book, or how a concept introduced at the end of the course was introduced in the beginning of the book in less detail."

"the maps can help you find out exactly what was covered, and what was being covered in other courses, and when. (You can also) build upon students' knowledge of similar concepts or indicate to them how a concept in one particular course is similar or dissimilar".

Finally, students commented on how the actual creation of the maps also served as a helpful exercise for them as a student:

"For a student who is making the curriculum map throughout the year, if one assumes that the professors will try to test everything at some point, one can quickly glance down the columns, count the number of lectures devoted to a certain topic, see what was already tested and make some estimations as to what will be on the midterm/quizzes/exam."

"Assuming the curriculum map is done simultaneously with the progression of the course, it provides the student with a quick review of each lecture, allowing for better retention of what was done in class."

"One learns how to identify skills, which is useful for writing resumes and cover letters. Also, if curriculum mapping is maintained throughout the duration of the course, one would develop excellent organizational skills."

"Students learn to look at the course from the point of view of the professor and perhaps in this way, will better grasp the goals of the course."

\section{Professor Perspective}

The curriculum maps representing the first year curriculum were presented to faculty at a instructional meeting at the beginning of each semester, and faculty have been asked to review the maps, making suggested changes based on evolution of their course from the 2005/2006 to 
2006/2007 school year, and also to note some of the things that surprised them about students' perception of the course and learning objectives.

One instructor notes:

"The map is probably the most helpful in the following year. To serve as a check on how instructors are progressing. (Are you) ahead of last year, behind last year? It's also a good tool in assessing the past year (Did I really spend two lectures on that?!)”

Instructors also identified the advantages to seeing content and assessment linked, and the possibility of using the maps for cross-course integration:

"I particularly liked the "assessment" column. I'm always wondering if the tests and exam have been balanced in terms of material covered in the questions."

"the maps (can be used for) curriculum design... and integrating the math and science courses."

While the students experienced uncertainty around their conceptualization of course learning objectives, instructors were impressed with the students' perceptions:

"When I first saw the map, I was really impressed by the student's ability to articulate the learning objectives, perhaps better than the prof could do him/herself! I was impressed by the student's ability to come up with this list but I am not convinced the prof would have been able to come up with this list or would have perhaps come up with a different list. Is it possible that the prof could think he/she has a certain set of learning objectives in mind but the student actually takes away a different set of outcomes? If so, is this a bad thing?"

\section{Next Steps \& Conclusions}

What has been presented is the first phase in the project. Now that we have highly detailed accounts of our entire first year curriculum and we are on our way to the same for our second year curriculum, there are several "next steps" to embark on in having a comprehensive understanding of our new curriculum, which will include the input of both students and faculty. The following briefly outlines the direction for our curriculum mapping project:

- For individual courses, determine if the various map components show coherence, lectureby-lecture. Compare contents of the map against course learning goals. Determine if content should be updated with timely curriculum. Are necessary skills and concepts included? Do students have the strategies to meet these objectives?

- Put together the maps for same or similar subjects across 2-4 semesters and look for evidence of continuity, repetitions or gaps.

- Put together maps across each individual semester to look for potential integration points, repetitions or gaps. For example, an early analysis of the maps demontrates that particular mathematical concepts are taught both in math and in physics courses, and are sometimes first taught in physics. Identifying this can help us make suggestions on how to re-structure 
the math curriculum, as possible, to better suit the needs of the science curriculum in the program.

- Look at the entire set of maps to determine "big picture" issues that may not emerge from viewing individual courses, disciplines or semesters.

Another aspect of this project will be the development of a program syllabus, with a very specific set of skills and desired knowledge for all students that progress through our program, and the determination of whether these are being met by examining their existence through individual courses. In this particular type of map, as noted by Maki (2004) ${ }^{7}$, one can specify the level at which a skill or piece of knowledge is taught - for example, by using a code like "I=introduce, $\mathrm{R}=$ reinforce, $\mathrm{E}=\mathrm{emphasize}$ " - and then determine whether changes need to made to ensure we are delivering curriculum that meets our overall program objectives.

Based on our experience thus far, we believe that the possibilities for a well-documented, wellorganized and public curriculum map are plentiful. We are already seeing the benefits to having a better understanding of the curriculum, in particular through the identification of new opportunities for integration in the first year. In addition to the traditional benefits to curriculum mapping, we feel there are other potential uses for a curriculum map. As a professional program, curriculum maps could be used by accreditation representatives to achieve a solid understanding of our "real" curriculum. Graduate schools and engineering companies may find curriculum maps useful in achieving a better understanding of the skills and knowledge base of the engineering graduate.

By engaging students in the process, we have added a unique element to the nature of curriculum mapping. Through student involvement, students have the opportunity to express their perceptions of the curriculum and what they have learned, and faculty can see how students have perceived the learning objectives and overall goals for the course. If the perceptions of the students differ from the instructors' set goals, there is an obvious need to look at course delivery and whether instructor objectives, delivery and assessment are in sync.

We will know we have succeeded when we see improvements in student learning where we have strived to re-align and better integrate curriculum, and when ongoing mapping and review is accepted as a meaningful practice for all instructors, students and administrators involved. We are well on our way to creating a more meaningful learning experience for our students and look forward to continued work in the mapping project.

Bibliography

1. Bransford, J.D., Brown, A.L. and Cocking, R.R., editors (1999). How People Learn: Brain, Mind, Experience and School. (Washington, DC: National Academy Press).

2. Clough, D.B., James, T.L. and Witcher, A.E. (1996). Curriculum Mapping and Instructional Supervision. NASSP Bulletin, 80: 79-82. 
3. Declark, T. (2002). Curriculum Mapping: A How-To Guide. The Science Teacher, 69: 29-31

4. Gjerde, C.L. (1981). 'Curriculum Mapping': Objectives, Instruction and Evaluation. Journal of Medical Education, 56:316-323.

5. Harden, R.M. (2001). AMEE Guide No 21: Curriculum Mapping: A Tool for Transparent and Authentic Teaching and Learning. Medical Teaching, 23:123-127.

6. Jacobs, H.H. (2004). Getting Results with Curriculum Mapping. (Alexandria, VA, Association for Supervision and Curriculum Development)

7. Maki, P.L. (2004). Maps and Inventories: Anchoring Efforts to Track Student Learning. About Campus, September-October Issue.

8. McKinney, E.H. and Yoos, C.J. (1998). The One School Roomhouse: An Information and Learning Approach to Curriculum Integration. Journal of Management Education, 22: 18-36.

9. Sumsion, J. and Goodfellow, J. (2004). Identifying Generic Skills Through Curriculum Mapping: A Critical Evaluation. Higher Education Research \& Development, 23: 329-346.

10. Wigal, C.M. (2005). Managing and Aligning Assessment Knowledge. $35^{\text {th }}$ Annual Frontiers in Education (pp T3C-13-18) Conference Proceedings. 